\title{
Conducting Research in a Developing Country: A Reflection-in-Action Perspective
}

\author{
Debra Burleson \\ Baylor University \\ debra burleson@baylor.edu
}

\author{
Wallace Chipidza \\ Baylor University \\ wallace chipidza@baylor.edu
}

\begin{abstract}
ICT4D researchers acknowledge the instrumental role of cultural differences in determining project outcomes. Rarely, however, do they acknowledge culture's role in the actual research process. This study explores the impact of cultural differences on research conducted by Western-based researchers in a developing country. In mid-2015, we went to Uganda to conduct research on mobile payment systems and technology use in healthcare. This study recounts our data collection process, particularly the unique challenges and opportunities that we experienced. We employ the theory of reflection-in-action to interpret our responses to disruptions to our research project. As part of our contribution to ICT4D research, we offer several recommendations for conducting research in a developing country.
\end{abstract}

\section{Introduction}

Most ICT4D projects are initiated by agencies from the Western world, on behalf of communities in the Global East or Global South. More generally, powerful agencies initiate these projects on behalf of marginalized communities [12]. As is documented in the literature, conflicts may arise from this reality; for example, a networking project meant to benefit the Taiwanese Aboriginals was declared a success by the government, yet the Aboriginals felt that the ultimate goal of improving their children's education was not met [12]. We observe that power disparities between benefactors and beneficiaries affect not only the execution of the projects, but also the assessment of project outcomes. As observed in [12], power disparities might result in the de-voicing of beneficiaries. In other words, the benefactor is commonly the declarer of success (or failure), while the beneficiary's voice is forgotten in the assessment process. To mitigate this problem, researchers interview and survey the intended beneficiaries of ICT4D projects in order to understand the latter's views. We posit that the evaluation process (i.e. the interviews, surveys, participant observation etc.) is not immune to the influence of cultural differences between researchers and participants.

In their seminal review of the role of culture in IS, Leidner and Kayworth [10] summarized the impact of culture on IS issues such as the use and development of ICTs, and the applicability of Western-originated management theories to developing countries. Most ICT4D studies recognize the importance of local culture in influencing project implementation and success [8,22]. However, the research process is seldom subjected to the same requirements for crosscultural awareness that ICT4D project implementation and evaluation are subject to. Rather, researchers routinely state that they conducted interviews, observed participant meetings, and conducted surveys $[7,18]$, and they neglect details of difficulties and problems faced [16]. This implies that cultural differences have little impact on the research process, and that, for example, a research program developed in the U.S. can be used in Rwanda with little to no modification.

But the implied assumption is incorrect. Research conducted outside a researcher's familiar zone will be different than research conducted on his/her own home turf. There are additional constraints imposed by the transition in context which are exacerbated as the cultural gap between researchers and participants widen. Research done in another country usually has a strict time boundary, thus limiting the researcher's ability to modify surveys, for example, especially if access to printing resources is difficult, which is often the case in developing countries. In addition, language might be a barrier between researchers and participants. A translator might help bridge this gap, but some countries have dozens of languages, which makes it impractical to use translators. And countries have different timekeeping cultures, which might delay and ultimately derail a research project [13]. These constraints complicate the research process, and it is important to prepare for them, in case they disrupt the research project. 
This study narrates the data collection process for a research project conducted in Uganda. The project aimed to understand how Ugandans use mobile payment systems, and to identify opportunities for information technology use in healthcare. Our motivation from this paper stems from the struggles to accomplish our research goals. We realized that our reliance on published guidelines did not fully prepare us for disruptions to the project. Most guidelines for conducting research in developing countries emphasize the preservation of ethics especially in medical studies, and rightly so $[5,20]$. But in our opinion, there is little focus on the actual research process, and how cultural differences can impact it. We contend that culture is a pervasive influence on the process, and it affects virtually every facet of research, i.e. timing, length, interview tone, and survey administration etc.

It is important to emphasize the boundaries of this paper. We are not reporting on the results of our research project, rather we are telling the story of how we collected the data. The paper is organized as follows. First, we present an overview of the literature. The next section outlines the theoretical foundation of the study. We then tell our story, discuss its theoretical and practical implications, before listing the study's limitations and concluding.

\section{Literature Review}

The IS field has shifted its focus from the discussion of whether or not ICTs are relevant in developing countries to the implementation of ICTs in developing countries [23]. Clearly, culture can significantly impact IT implementation [10]. National culture can impact organizational failures and has dramatic influence on people's communication and technology choices. including information processing and transmission. In fact, even the artifacts used to communicate are not culturally neutral. Further, research in the areas of sustainability and healthcare address issues of culture and context, yet the research process remains unchanged - a seemingly flawless process - and ignores the same culture and context that is at its core [7].

Clearly, culture influences ICT4D outcomes, yet little attention is paid to culture's influences on actual research processes. In order to understand the potential effects on research processes, we examine the dramaturgical model [6], which has emerged as a powerful metaphor for guiding qualitative interviews [16]. Based on the metaphor of the theatre, face to face interactions such as focus group and one-on-one interviews are viewed as theatrical plays, with the interviewer and interviewee as actors [16]. Shared norms, rituals, and behavioral expectations constitute the script to be followed when acting out the play. In a situation where both the interviewer and the interviewee originate from the same context, the script is relatively easy to follow because of overlap in cultural values and norms. However, in cross-cultural research, there might be limited overlap in norms between researcher and participant. This suggests that the dramaturgical model is not immediately portable to cross-cultural research.

This paper joins a growing stream of research that encourages greater cultural awareness in research design. Brunello [2] situated his study in the broader context of the differences between his original (Belgium) context and the Burundi context. By emphasizing differences between Belgium and Burundi in factors such as life expectancy, literacy, and school enrollment, the study illuminated the role of contextual differences in influencing attitudes toward innovation by the different study participants. Further, the research project faced constant disruptions owing to electricity blackouts. In an earlier study, Brunello [1] had detailed an ethnographic study that acknowledged not only the evolution of the research setting but also the relationship between researcher and participants.

In a ten-month long ethnographic study, Nemer [17] examined the web practices of Brazilians living in favelas. He highlighted the power differences between his participants and himself, and noted how ethnography centers the research on participants from marginalized communities. The above studies emphasize the inclusion of participants, but the solutions typically entail ethnographic solutions that require long periods of physical interaction with participants. Our study addresses time-constrained research in developing countries, without necessarily altering existing research methodologies.

\section{The Theory of Reflection-In-Action}

The main thesis of this theory is the distinction between theoretical or technical knowledge, and practical knowledge. It was formulated by Schön [19], in response to the inadequacy of technical rationality storing knowledge in students so that they could use it in professional practice [19] - in solving problems encountered by professionals. The traditional view of professional practice emphasizes pre-determined problems, but real world problems are often puzzling and complicated. Reflection-in-action emphasizes the simultaneity of reflection and action [19]. Reflection is commonly an ex post action, meaning that an individual experiences an event, and only reflects on it after its conclusion [25]. However, in most 
professional practice, events entail a fluidity that mandates real-time and spontaneous reactions. For example, a software developer might encounter an unprecedented error when attempting to compile a program; he/she will not typically wait until day-end to reflect on the error, no matter how unprecedented the error might seem. Rather, the developer will both reflect and act simultaneously to solve the problem. The term reflection-in-action, reflects this simultaneity.

The theory has three main steps: appreciation, reappreciation, and action [19]. Appreciation is a process where the professional frames the unique problem; action is the experimental process that attempts to solve the problem; and re-appreciation is the professional's evaluation of the experiment's outcome $[11,19]$. Accordingly, what is taught through academic training requires modification in practice. In the course of conducting their responsibilities, individuals face unique and uncertain circumstances which require them to respond through knowledge application [19]. Up until the need for application is necessitated, codified knowledge mostly constitutes the entirety of the knowledge repertoire of the professional. Figure 1 below shows how a team of researchers might respond to disruptions in their research program using reflection-in-action.

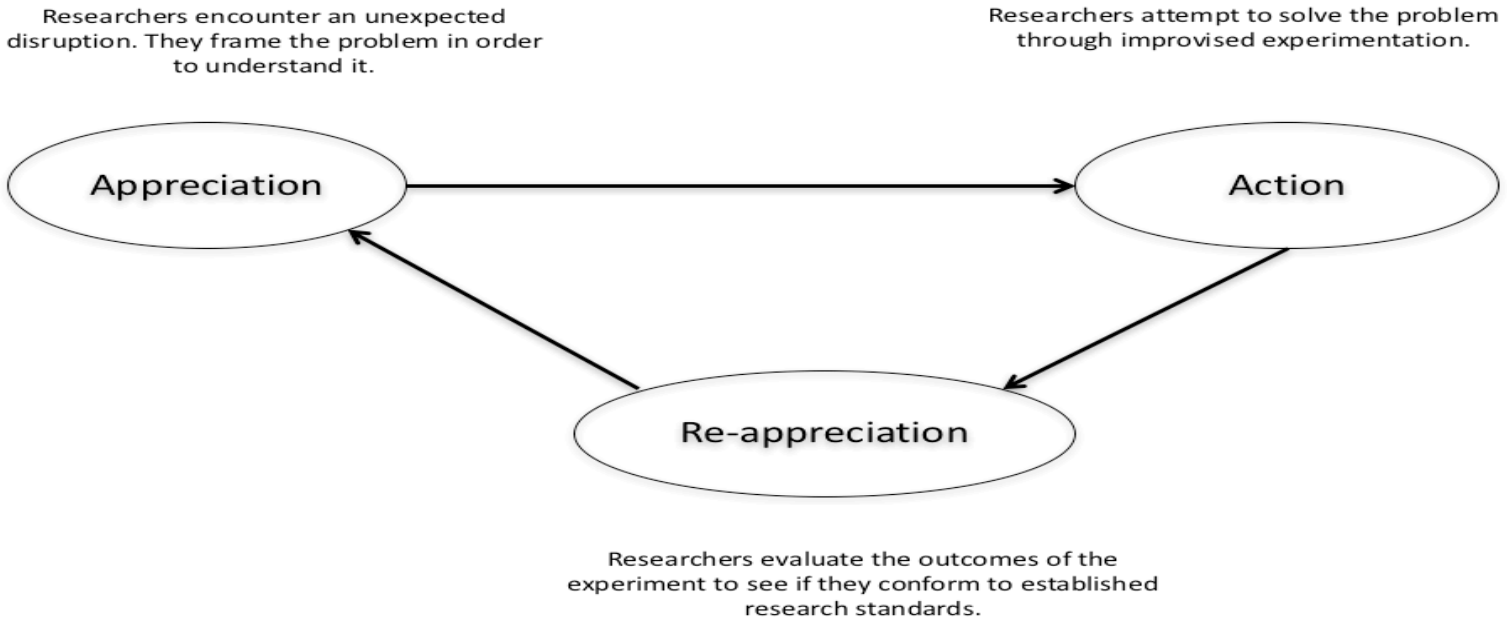

Figure 1: Reflection-in-Action in Cross-Cultural Research

Reflection-in-action is a useful lens for understanding how Western-based researchers might respond to unique and uncertain circumstances when placed in unfamiliar research contexts, such as in developing countries. Such researchers have to question the assumptions undergirding much of the published guidelines on doing research. A trigger of reflection-in-action is "back-talk", or when the materials of focus in a situation surprise the professional [25]. This unexpected back-talk requires the researcher to improvise his/her reaction: the novice researcher does not have an experiential base to draw from when faced with situations not covered in his/her research seminars, and the experienced researcher might have conducted research only in Western contexts. When placed in a developing country context, stored knowledge may thus prove inadequate if there are unexpected disruptions to the research program. Faced with this knowledge deficit, researchers have to simultaneously reflect and act in order to accomplish their research objectives.

The literature houses many guidelines on how to conduct qualitative research [18], mixed methods research [10], and research in developing countries [23]. These guidelines emphasize the importance of context. However, context varies widely. This makes it difficult to write guidelines that are general enough to encompass all contexts. As a result, the effectiveness of codified research guidelines also varies from context to context. This variability complicates the ability of researchers to effectively conduct their studies. In contexts where codified knowledge is inadequate, researchers have to modify their knowledge to cope with unique and unusual circumstances. In Schön's words, improvisation forms a vital component in the performance of practice [19].

As we sought to collect information from participants of our study, we found that the useful guidelines that we understood from the literature illequipped us for the actual context that we meant to understand. In a foreign place where local culture and norms dictate how the research is conducted, researchers have to cede some control to the contingencies of the context. Although researchers 
attempt to gather all the information necessary to successfully accomplish the research in a developing country context, information gaps still remain. For example, study participants might not show up, especially in areas where transport costs are significantly high. Or the researchers' flights might be delayed due to inclement weather. These are examples of contingencies that are hard to codify in guidelines, but might still play a destabilizing role in a research study. The ability to react to such unfortunate emergencies can still salvage the research project.

Reflection-in-action is a dignified response to surprising developments [25], and it helps avert crises that require urgent resolution. It allows the researcher to wrest control back from disruptive contingencies.

\section{Data Collection: Situating and Reflecting}

In May 2015, we travelled to Uganda with a larger group from our university. The group's focus was to lead business seminars and one faculty member coordinated this group. Our role as researchers was not entirely separate from the coordinator's role as we would be conducting research during the break times of the business seminars. In short, we also had to be sensitive when scheduling our research time to not interrupt the seminars. Our goal was to conduct two research projects. The first project aimed to understand the impact of mobile payment systems on the everyday lives of Ugandans, and the second project aimed to identify opportunities for the use of information technology in the Ugandan healthcare system. Before traveling to Uganda, we studied the culture and the challenges in healthcare services and in mobile banking. We had done research outside our home countries, and felt that we understood the importance of context and culture. We also anticipated issues that we might have as we conducted our research in a developing country. What technologies did we need to take with us? Would the Ugandans volunteer to participate in our focus groups? Would we be able to relate to one another? There were also areas that we had no control over nor could we modify. These areas included the research site, the cultural differences, and the participants' reaction to our topics (i.e. What if they did not want to answer any questions regarding banking? Would questions about money be too personal?).

Some challenges that we anticipated instead proved to be very positive experiences. To prepare for our research in Uganda, we conducted two focus group sessions while in the U.S. via Skype with the Ugandans. We arranged a meeting time based on a convenient time for our participants, which was late in their work day and very early in ours. Several of the participants had frequently Skyped with individuals in other countries, so they were familiar with the technology. We had little confidence that the Internet connection would be sustainable for two 45-minute sessions. We also were prepared to compensate them for the cost of the Skype session; however, the call for them was free of charge. Therefore, the Internet bandwidth was more than adequate, the connection was not an issue, and it was free. We videotaped our Skype sessions, using the same equipment and going through the same protocol as we would do once we were in Uganda.

Our overall goal for the research study was to develop a plan for ICT solutions with future implementation. Keeping in mind that the use of mobile devices was central to our protocol of questions, we asked a question about contacting healthcare professionals. When we asked this question, "What if you were able to contact your doctor or a nurse at the clinic by texting them?", during the pilot focus group sessions, instead of answering the question, the participants almost simultaneously laughed. Their response meant that they could not conceive of the thought that they might be able to text their doctor or nurse. It was at this point that we realized that there was no point in asking the follow-up questions because the questions were designed to delve further into ICT opportunities that we might explore. We reevaluated the questions, revised our protocol, and conducted our second focus group. As a result, our participants completed our questions and the quality and potential outcome of our research significantly improved.

We also piloted the survey. To do this, we emailed a pdf copy of the survey, and our local contact printed hard copies. We consulted via Skype with the coordinator to get the group's impressions of our questions, the wording, etc. For example, one question asked participants how much income they earned annually. We needed to revise it to conform to Ugandan currency standards and also added a notation that the question was optional. The group felt that this question should not be required because it was too personal, even though we were not asking their names. We also wanted to know if our participants lived in the city or in a village. The group made suggestions regarding wording. For example, while they talk about their villages, they do not refer to living in a village but rather living in the greater Kampala (Uganda's capital) area. Therefore, we revised our survey from the choice of living "in a neighboring village," to the "greater Kampala area." Although this might have seemed a subtle change in wording, the change communicated 
that we understood their context and we adjusted to our differences rather than our participants having to adjust to unfamiliar wording.

In preparation for our research, we had piloted our surveys and focus group sessions, travelled long distances, and believed that we could maximize the short two and a half days that we had to gather our data. We travelled with a larger group who were conducting business seminars for adult Ugandans. Our research site was held at the same location as the seminars because our participants were attending the seminars and the local coordinator assured us that the site venue met our needs. Because seminar agendas were preset, we had to fit our study within the timeframe of the seminars. Therefore, our focus group participants agreed to either come early before the seminars or stay after. If needed, we also had flexible time during the lunch hour for focus group sessions. The surveys were distributed on the final day of the session.

Although we believed that we were prepared, we experienced unexpected and stressful challenges. These challenges could have easily disrupted our research to the point of jeopardizing the project. In addition, while we prepared for the broad context-a developing country-we had not fully prepared for the context for our participants. In order to implement our research project and collect our data, we had to quickly improvise within the parameters of our IRB process, seek solutions that did not inhibit our participants or compromise our data, and work within our time constraints. Table 1 categorizes the disruptions we encountered according to the two methods--focus groups and surveys--that we used. We then categorize the context of these disruptions and overlay the Theory of Reflection-In-Action (Appreciation, Action, and ReAppreciation).

Once in Uganda, our research site proved very challenging. The planned site was intended to be a hotel with conference rooms; however, it was not available when we arrived. Instead, our site was a gymnasium, which included two separate side rooms. Because the site was not fenced, local organizers felt that security should be hired. Therefore, we had armed guards outside of our research site. At the beginning of each day's session, the large group of approximately 200 Ugandans gathered for announcements. On day one, we recruited our participants during this session. We introduced ourselves, gave an overview of our research, and clearly communicated that we were interested in their perspective. We emphasized the last point stating that we were not Ugandans, yet we believed that our research could help towards solving some issues that they faced. We shared that we needed them to tell us what it was like to live in Uganda, specifically, their perceptions of accessing healthcare facilities and banking using mobile devices. As individuals raised their hands to volunteer, we asked them to meet us at a specific location in the building. We were intentional about recruiting a balance of males and females. Once we met with them, we shared that we would give them a thank you gift for the time they spent with us if they completed both focus group sessions.

In addition, we planned to conduct two focus groups simultaneously in two separate rooms. However, the facilities at the site required us to use a large room with concrete floors, with a large rolling chalkboard dividing the room. During our first focus group session, we made adjustments. These adjustments included positioning the two focus group participants so that they faced in opposite directions, and agreeing to speak quietly. With that plan, we turned on our video cameras and hoped for the best. At the beginning of the session, we could hear our participants, however, and as the session progressed, other seminar attendees began walking into our area and we could no longer hear our participants.

We consulted about the physical space, talked with the organizers, and located a second smaller room. The room was not part of the rented space and special provisions had to be made to use it. After several conversations, the facility's manager agreed to let us use the room. The problem with the room was that it was extremely hot because we could not open the windows due to the noise outside. However, the room would provide a quiet space. For the next round we decided to put one group in the original room and one group in the private room. We asked a local seminar facilitator to secure the original room and prevent early seminar arrivers from entering during our sessions. The original room was a very long room, and we used the space at the far end of the room, keeping the moving chalkboard in the middle. We also added an additional recording device - our mobile devices_as a second recording device. The camcorder was mounted on a tripod and was a short distance from the focus group. The mobile device recorder allowed us to move the device around the table and position it so that each person's comments could be recorded. It was interesting that this additional device increased the participants' awareness of the seriousness of our intent to hear their stories. While this proved much more effective than the first attempt, we eventually alternated using only the private room. We explained that the change to the private room was to help us hear them. We also continued to use the mobile device to ensure that comments were audible. Even though the private room was extremely hot and with no ventilation, we could understand our participants, and 
the quality of the video recordings was adequate.

In addition to adjusting the physical space, we also had to adjust the time allotted for each focus group session and make changes. We emphasized to our participants the importance of their perspectives and their stories, and they believed us to the point that each person wanted to answer every question. Often the participants shared information that had been stated. So, we discussed this at length as researchers because focus group sessions were extending beyond the time that we had been allotted during the business seminars. In the Ugandan culture, a personal relationship takes precedence over a deadline. So, we understood why they did not seem concerned about the sessions extending over the time yet we would not be able to complete the number of focus group sessions if we did not adhere to our schedule. Therefore, we explained that because we wanted to meet with at least 40 participants and had only the time allotted, that we needed to move onto the next question unless they had additional information. We also wrapped up the questions and moved on to the next question with more deliberate intent. This strategy worked, and we were able to complete each focus group in the amount of time we had designated.

Table 1: Researcher Responses to Disruptions to Research Project

\begin{tabular}{|c|c|c|c|c|c|}
\hline $\begin{array}{c}\text { Research } \\
\text { Method }\end{array}$ & Disruption & Context & Appreciation & Action & $\begin{array}{c}\text { Re- } \\
\text { Appreciation }\end{array}$ \\
\hline \multirow{4}{*}{$\begin{array}{l}\hat{O}_{3} \\
0 \\
0 \\
0 \\
0 \\
0 \\
0 \\
0\end{array}$} & $\begin{array}{l}\text { A potential future } \\
\text { intervention was } \\
\text { introduced in a pilot focus } \\
\text { group session and the } \\
\text { participants could not } \\
\text { envision the possibility of } \\
\text { the intervention. }\end{array}$ & $\begin{array}{l}\text { Culturally } \\
\text { challenged }\end{array}$ & $\begin{array}{l}\text { We reflected on } \\
\text { their response } \\
\text { and revised our } \\
\text { questions. }\end{array}$ & $\begin{array}{l}\text { We conducted a } \\
\text { second pilot focus } \\
\text { group. }\end{array}$ & $\begin{array}{l}\text { Participants } \\
\text { understood the } \\
\text { questions and } \\
\text { the concepts } \\
\text { introduced. }\end{array}$ \\
\hline & $\begin{array}{l}\text { The focus group site was } \\
\text { noisy and both the } \\
\text { participants and } \\
\text { researchers had difficulty } \\
\text { hearing each other. }\end{array}$ & $\begin{array}{l}\text { Research } \\
\text { site }\end{array}$ & $\begin{array}{l}\text { We listened to } \\
\text { the recording of } \\
\text { the first group } \\
\text { and realized that } \\
\text { we needed to } \\
\text { make } \\
\text { adjustments. }\end{array}$ & $\begin{array}{l}\text { We added an } \\
\text { additional } \\
\text { recording device } \\
\text { that could be } \\
\text { moved closer to } \\
\text { the participants. } \\
\text { We also changed } \\
\text { the location of our } \\
\text { focus groups } \\
\text { within the existing } \\
\text { venue. }\end{array}$ & $\begin{array}{l}\text { We were able to } \\
\text { hear our } \\
\text { participants and } \\
\text { they were able } \\
\text { to hear us. }\end{array}$ \\
\hline & $\begin{array}{l}\text { The participants spoke in } \\
\text { a very soft tone and their } \\
\text { accents were difficult to } \\
\text { understand. }\end{array}$ & $\begin{array}{l}\text { Culturally } \\
\text { challenged }\end{array}$ & $\begin{array}{l}\text { We listened to } \\
\text { one recording } \\
\text { and made notes } \\
\text { of responses that } \\
\text { were confusing. }\end{array}$ & $\begin{array}{l}\text { We asked the } \\
\text { participants one on } \\
\text { one after the } \\
\text { sessions to clarify } \\
\text { our notes. }\end{array}$ & $\begin{array}{l}\text { We re-listened } \\
\text { to the first } \\
\text { session with the } \\
\text { amended notes } \\
\text { and were able to } \\
\text { continue our } \\
\text { focus groups, } \\
\text { listening and } \\
\text { understanding } \\
\text { our participants' } \\
\text { responses. }\end{array}$ \\
\hline & $\begin{array}{l}\text { Each participant wanted } \\
\text { to share his or her detailed } \\
\text { response for every } \\
\text { question. }\end{array}$ & $\begin{array}{c}\text { Time } \\
\text { Limitation }\end{array}$ & $\begin{array}{l}\text { We realized that } \\
\text { we would not be } \\
\text { able to complete } \\
\text { each focus group } \\
\text { in its allotted } \\
\text { time. }\end{array}$ & $\begin{array}{l}\text { We emphasized } \\
\text { our instructions, } \\
\text { adding a statement } \\
\text { of each } \\
\text { participant's value } \\
\text { and also of our } \\
\text { time constraints. }\end{array}$ & $\begin{array}{l}\text { We were able to } \\
\text { complete our } \\
\text { focus group } \\
\text { sessions within } \\
\text { our time frame. }\end{array}$ \\
\hline
\end{tabular}




\begin{tabular}{|c|c|c|c|c|c|}
\hline $\begin{array}{c}\text { Research } \\
\text { Method }\end{array}$ & Disruption & Context & Appreciation & Action & $\begin{array}{c}\text { Re- } \\
\text { Appreciation }\end{array}$ \\
\hline 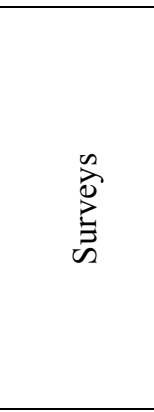 & $\begin{array}{l}\text { Pilot survey participants } \\
\text { felt the survey was too } \\
\text { short. }\end{array}$ & $\begin{array}{l}\text { Participant } \\
\text { desires vs. } \\
\text { traditional } \\
\text { research } \\
\text { approach }\end{array}$ & $\begin{array}{l}\text { We reviewed the } \\
\text { questions and } \\
\text { their comments } \\
\text { and realized that } \\
\text { we could ask for } \\
\text { more } \\
\text { information. }\end{array}$ & $\begin{array}{l}\text { We revised the } \\
\text { questions and } \\
\text { asked more multi- } \\
\text { layered questions }\end{array}$ & $\begin{array}{l}\text { Participants } \\
\text { completed the } \\
\text { revised survey } \\
\text { and there were } \\
\text { not any } \\
\text { additional } \\
\text { negative } \\
\text { comments } \\
\text { regarding } \\
\text { length. }\end{array}$ \\
\hline 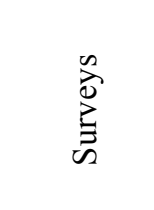 & $\begin{array}{l}\text { Some participants did not } \\
\text { understand the Likert } \\
\text { scale (i.e. assigning a } \\
\text { number to a feeling) }\end{array}$ & $\begin{array}{l}\text { Culturally } \\
\text { challenged }\end{array}$ & $\begin{array}{l}\text { We revisited the } \\
\text { Likert scale and } \\
\text { understood how } \\
\text { it could confuse } \\
\text { our participants }\end{array}$ & $\begin{array}{l}\text { We delivered a } \\
\text { mini tutorial on } \\
\text { Likert scales }\end{array}$ & $\begin{array}{l}\text { We walked } \\
\text { around to } \\
\text { participants to } \\
\text { make sure that } \\
\text { they understood. }\end{array}$ \\
\hline
\end{tabular}

We distributed the surveys on the final morning of the seminar because our participants had more time on that day to complete the surveys than the two previous days. Also, they were seated at tables for the final large group session and the surveys would be easier to complete on a hard surface. Not all of the questions involved selecting an option or checking a response box. One of the surveys had a series of short answer questions. It was at this time that we experienced a unexpected challenge because the coordinator of our larger group asked us how long our participants needed to take the surveys and how many questions were on the survey. When we told them that we had 23 questions, the coordinator informed us that he would never have allowed us to give the survey because of the length. He had not done surveys in Uganda but was insistent that the Ugandans would not answer all of the questions. We shared our preparation, the pilot focus surveys, the positive reaction from the Ugandans, and our confidence that they would complete the surveys. We then proceeded with distributing our surveys.

As we began to distribute our surveys, we quickly realized that many participants were having difficulty with one of the surveys. We observed them asking each other questions and looking confused. We quickly discovered that they did not understand the Likert scale. Therefore, we adjusted by distributing the survey to participants in groups of three. With each group of three, we explained the Likert scale continuum and answered any questions that they had about the scale. This took additional time as we had approximately 200 participants, however, we had added additional time in our schedule for unexpected surprises.

We believe that most participants completed the survey because we explained our needs; we told them their information was important to us; and we were genuine. Ugandans seem to appreciate and value stories, and they responded positively when we listened to their stories through focus groups and asked questions via the survey. Also, thirty-five of the two hundred participants met us during the focus group sessions. We could see them pointing to us with nods of approval and talking to their friends, and we knew that we had gained their trust and that they were validating that trust to their friends. When we collected the surveys, our participants had answered most questions. In fact, many participants thanked us for the opportunity to share their information. They kept reminding us that the research we were doing was important.

In spite of the challenges, we modified our knowledge in order to cope with the situation. We did this by following the process of identifying the problem, appreciation; attempting to solve the problem, action; and reevaluating the outcome to verify research standards were met. Many times, these modifications had to happen in real time.

\section{Lessons Learned - Implications for research in developing countries}

Research involves preparation and patience. That said, research in a developing country adds a dimension that may be beyond what the researcher has encountered. This type of research demands flexibility, attention to detail, and a calm demeanor because this research depends on participant trust. IRB processes are critical. Each step in the research process needs to be evaluated based on the end goal. Yet, the processes that the researcher is familiar with may not be effective for the types of situations we will describe. Below, we 
offer the lessons learned from this study.

\subsection{Avoid setting low expectations for your participants}

In the West, we are used to reluctant participants because Westerners are often survey weary. We also may design online surveys with a segmented time scale, fully aware that Westerners have a time limit and also want to know how many segments are left as they progress through the survey. However, it is possible that people in developing countries might appreciate the fact that their opinions are valued, hence they might be more willing to complete longer surveys compared to Westerners. Western-based surveys tend to ask questions based on a scale. It takes less time, it is easy to quantify, and it is succinct. However, if the participants do not understand the scale, such as a Likert scale, results will be invalid. Also, in countries where the populations rarely quantify feelings such as strongly dislike or always like, these scales are confusing.

\subsection{Identify context-specific opportunities}

In countries where citizen opinions are rarely sought by governments or even private companies (advertising being one-way), participants might welcome the opportunity to participate in surveys or in focus groups. Researchers are typically professors whose opinions are valued by their peers and their students. While the researcher values the opinions of the participants, these same participants may not have experienced anyone seeking and validating their stories and life journeys. For example, in a focus group setting, researchers may experience this to the extreme: they may want to continue to the next question yet each participant may want to respond to each question and resist moving to the next question until everyone has had an opportunity to respond.

\subsection{Research cultural norms}

The researcher must also ensure that his/her solution to a contingent problem does not offend local customs. This is accomplished through extended interactions with people from the research context. The researcher should ask questions about conversation, timekeeping, and farewell norms etc. and listen carefully and respectfully to local representatives. For example, in our first focus group session, several participants spoke for long stretches of time and veered off-topic. Interrupting our participants might have been viewed as insulting, hence we waited until the next session to emphasize the need to stay on point. Had we not considered the cultural implication of interrupting an adult in Uganda, our focus group interviews might not have yielded optimal insight from participants.

\subsection{Utilize local resources}

Are there alumni from the research team's school who are based in the country where the research will be conducted? Are there current or former colleagues who might be able to identify contacts? These individuals have a lot more knowledge about the local context, and they also have a better understanding of what the researchers need than their locally trained counterparts. Partner with these people who could provide connections as you recruit participants. Developing this partnership takes time. Communicating about the research process, goals, and plans may involve multiple video conferencing sessions, calendaring weeks in advance of each session. Also, partnering involves a benefit to both the researcher and the partner. Often, findings from the research are important and extremely helpful for the partner who lives in the developing country. Research findings might educate the partner on weaknesses in technology artifacts; hence providing opportunities for improving service delivery. Therefore, co-operative behavior can be a very rewarding process for both the partner and the researcher.

Finally, it is important to utilize local services when carrying out research in a developing country. Services such as transcription are better performed by people who understand the local accent and local idioms. We employed an American service provider to transcribe our focus group interviews, and they were not able to understand significant fractions of the interviews. Had we not kept detailed field notes, we might have lost valuable information from these interviews, or we might have needed to spend additional money in order to attain better transcripts.

\section{Theoretical and Methodological Implications}

There are increasing calls for the IS field to conduct studies in developing countries. For example, Information Systems Journal recently sent out a CFP for a special issue in ICT4D [26]. And most of our conferences i.e. HICSS, ICIS, and AMCIS have minitracks devoted towards ICT4D. These developments are laudable, and they signal that ICT4D is now firmly established in the broader IS field. However, most ICT4D research studies focus on project evaluation, and particularly on identifying the critical factors 
necessary for project success. An unstated assumption in these studies is that the research process is flawless, and researchers only have to follow published methodological guidelines. Very few studies describe the context-specific problems that Western-based researchers are likely to encounter when conducting research in developing countries. A notable example of a study that alluded to such problems may be found in [12], where the researchers acknowledged that obtaining accurate project evaluation information from the beneficiaries required a long time. Such problems might disrupt research programs and cost institutions valuable finances. This paper aims to identify and understand these problems, for the benefit of others in the community of ICT4D and cross-cultural scholars.

This paper highlights how reflection-in-action can benefit a researcher when faced with disruption. Previous studies have employed reflection-in-action to understand multi-party collaboration in IS development, teaching, and in business process reengineering $[3,11]$. We extend reflection-in-action by showing how it enables researchers to simultaneously reflect and act in case of disruptions. We also show how culture and societal norms add a layer of complexity on the decision of the researcher; it is not enough to consult codified guidelines on how to do research, or even to rely on experience, rather, Our reaction was in the mold of practical reflexivity [25] as problems unfolded, we reflexively responded to salvage our research project.

Beyond theoretical implications, our study also has methodological implications on the dramaturgical model of conducting qualitative research in developing countries. First, in contrast to the model, neither the interviewer nor the interviewee may be in control of setting the stage for the interview. Rather, this role might be relegated to local intermediaries, as was the case for our study. If the researcher has limited control in setting the stage, gathering quality data might prove problematic. Further, the dramaturgical model assumes substantial overlap in norms, values, and behavioral expectations between researchers and participants [16]. This assumption is reasonable when the researcher and participants hail from the same context, but falls short when cultures collide. For example, Americans are strict timekeepers, whereas Ugandans seem more flexible in their timekeeping habits. In the dramaturgical model, the interviewer follows a script whilst the interviewee is expected to improvise. Yet in this study we show the importance of improvisation for the interviewer too, because $\mathrm{s} /$ he has to contend with surprises stemming from the context. In this regard, any cross-cultural interview might be more accurately viewed as improvisational theater. In other words, variations in context determine the effectiveness of the dramaturgical model.

\section{Study Limitations}

This study has limitations. First, our study details the struggles we encountered when conducting research at a specific location in Uganda. We cannot claim that these struggles are generalizable to all developing countries, or even to Uganda as a whole. Nevertheless, we hope that our recommendations are applicable to any cross-cultural research, and will help researchers accomplish their goals. Second, our research project employed interviews and surveys; hence, our observations might be limited by the methodology. It is possible that had we employed other methods such as participant observation and ethnography, our generated insights might be different. Third, we were operating within a strict time boundary. Researchers with more temporal and spatial flexibility may enjoy higher levels of control over their circumstances. Therefore, time is an important dimension of context when conducting research in a developing country. We hope that other scholars will include details on their own struggles with the actual research process; this will expand the body of knowledge on such issues and ultimately improve the research.

\section{Conclusion}

When immersed in a research process that takes months to prepare for and travelling long distances to meet with participants, it can seem daunting when obstacles occur such as the ones we have described. These obstacles can potentially delay or stop the project. We recognize that research involves unexpected twists and turns despite advanced planning. However, we hope that our insights and experiences offer suggestions to those whose research takes them beyond their context and their culture.

This paper seeks to add to our body of research by focusing on the preparation phase of the research process, which includes more than the method, analyzing data, and reporting findings. We recognize that research methodologies like participatory design and ethnography center the research on participants in order to militate against the influence of culture and power differences [2], but our study aims not to alter existing methodologies, but to highlight these influences on useful methodologies such as surveys and focus groups. Preparation depends on understanding the context and culture of the participants and organizations. While much attention has been centered on how data is analyzed and how systems are put in place, research processes need to 
include allowances for cultural differences. Our discipline can position itself to make significant advances in areas such as healthcare and banking in developing countries. These advances depend on intentional awareness of culture, including research processes. Otherwise, we risk spending large amounts of time and funding on failed projects.

\section{References}

[1] Brunello, P. Charting the uncharted: ICT and education in Burundi. red-conference, (2011), 348.

[2] Brunello, P. Broken premises: Towards an intercultural understanding of bilateral co-operation in ICT for education in Burundi. (2015).

[3] Ciborra, C.U. Notes on improvisation and time in organizations. Accounting, management and information technologies 9, 2 (1999), 77-94.

[4] Creswell, J.W. and Clark, V.L.P. Designing and conducting mixed methods research. (2007).

[5] Edejer, T.T.-T. North-South research partnerships: the ethics of carrying out research in developing countries. British Medical Journal 319, 7207 (1999), 438.

[6] Goffman, E. and others. The presentation of self in everyday life. Harmondsworth, 1978.

[7] Ibrahim-Dasuki, S., Abbott, P., and Kashefi, A. The impact of ICT investments on development using the capability approach: The case of the Nigerian pre-paid electricity billing system. The African Journal of Information Systems 4, 1 (2012), 2.

[8] Jarvenpaa, S.L. and Leidner, D.E. An information company in Mexico: Extending the resource-based view of the firm to a developing country context. Information Systems Research 9, 4 (1998), 342-361.

[9] Johnson, R.B. and Onwuegbuzie, A.J. Mixed methods research: A research paradigm whose time has come. Educational researcher 33, 7 (2004), 14-26.

[10] Leidner, D.E. and Kayworth, T. Review: a review of culture in information systems research: toward a theory of information technology culture conflict. MIS quarterly 30, 2 (2006), 357-399.

[11] Levina, N. Collaborating on multiparty information systems development projects: A collective reflection-inaction view. Information Systems Research 16, 2 (2005), 109-130.
[12] Lin, C.I., Kuo, F.-Y., and Myers, M.D. EXTENDING ICT4D sTUDIES: the value of critical research. Mis Quarterly 39, 3 (2015), 697-712.

[13] Livingstone, S. On the challenges of cross-national comparative media research. European journal of communication 18, 4 (2003), 477-500.

[14] Marshall, C. and Rossman, G.B. Designing qualitative research. Sage, 2011.

[15] Myers, M.D. Qualitative research in business \& management. SAGE, London, 2013.

[16] Myers, M.D. and Newman, M. The qualitative interview in IS research: Examining the craft. Information and organization 17, 1 (2007), 2-26.

[17] Nemer, D. Rethinking social change: The promises of Web 2.0 for the marginalized. First Monday 21, 6 (2016).

[18] Pscheidt, M. Structurational analysis of cross-cultural development of an academic registry information system in Mozambique. Information Technology for Development 17, 3 (2011), 168-186.

[19] Schön, D.A. The reflective practitioner: How professionals think in action. Basic books, 1983.

[20] Varmus, H. and Satcher, D. Ethical complexities of conducting research in developing countries. New England Journal of Medicine 337, 14 (1997), 1003-1005.

[21] Vulliamy, G., Lewin, K., and Stephens, D. Doing educational research in developing countries: Qualitative strategies. Falmer Press London, 1990.

[22] Walsham, G., Robey, D., and Sahay, S. Foreword: Special issue on information systems in developing countries. MIS Quarterly, (2007), 317-326.

[23] Walsham, G., Robey, D., and Sahay, S. Foreword: Special issue on information systems in developing countries. MIS Quarterly, (2007), 317-326.

[24] Warwick, D.P. Social research in developing countries: Surveys and censuses in the Third World. Psychology Press, 1993.

[25] Yanow, D. and Tsoukas, H. What is reflection-inaction? A phenomenological account. Journal of management studies 46, 8 (2009), 1339-1364.

[26] Information Systems Journal - Special Issues - Wiley Online Library.

http://onlinelibrary.wiley.com/journal/10.1111/(ISSN)13652575/homepage/special_issues.htm. 